\title{
Customer Strategy for Implementing Customer Relationship Management in Corporation with the Value-Based Network Analysis Approach
}

\author{
Ebrahim Kalani ${ }^{1,2}$, Alireza Elhami' ${ }^{2}$ Mahshid Mashreghi' \\ Reza Baradaran Kazem-Zadeh', Ehsan Kamrani ${ }^{3}$ \\ ${ }^{1}$ Department of Industrial Engineering, Tarbiat Modarres University, Tehran, Iran \\ ${ }^{2}$ Department of Management, Khatam Al-Anbiya University, Tehran, Iran \\ ${ }^{3}$ Institute of Medical Science and Technology, Shahid Beheshti University, Tehran, Iran \\ Email: ekamrany@gmail.com
}

How to cite this paper: Kalani, E., Elhami, A., Mashreghi, M., Kazem-Zadeh, R.B. and Kamrani, E. (2018) Customer Strategy for Implementing Customer Relationship Management in Corporation with the Value-Based Network Analysis Approach. American Journal of Industrial and Business Management, 8, 537-547.

https://doi.org/10.4236/ajibm.2018.83035

Received: February 4, 2018

Accepted: March 17, 2018

Published: March 20, 2018

Copyright $\odot 2018$ by authors and Scientific Research Publishing Inc. This work is licensed under the Creative Commons Attribution International License (CC BY 4.0).

http://creativecommons.org/licenses/by/4.0/

\begin{abstract}
With the new technology, organizations increasingly recognize the importance of managing customer relationships, and many of them have been deployed to customer relationship management (CRM) in order to serve customers better and build close relationships with them. On the other hand, the recognition of valued customers and their management has become an important issue. In today's world, the business market is a complex network of tangible and intangible value relationships whose identification and optimal management is important. If these relationships are not optimally managed, it can lead to a great deal of harm to the organization and; on the other hand, if these relationships can be properly identified and managed, they can organize huge profits with the least cost. In this article, the target organization that focuses on the network, as well as its corporate clients, has been reviewed, and a model for explaining customer strategy for implementing CRM in a company (Saba Corporation in Iran) as an example has been presented. Further, on the characteristics of its customers, the organization's policy has also been implemented. To do this, first, corporate customers focus on the value they focus on (customer lifetime value or CLV), and then the value chain will be implemented across the different segments of the corporate customer focus. By implementing the value chain among the various sections of the corporate customers, the hub can design suitable marketing programs for managing value paths and allocate appropriate budgets for each path.
\end{abstract}

\section{Keywords}

Customer Relationship Management, Customer Value, Customer Lifetime 
Value, Value Network, Value Loop, Network Value Analysis

\section{Introduction}

The main purpose of this research is to provide a model for explaining customer strategy for implementation of customer relationship management (CRM) in a company [1] [2] [3]. Here we've chosen the Saba Corporation as a case study.

The process of the conducting research has been illustrated in Figure 1.

The CRM can be noted in various aspects:

- Provide a good methodology for explaining the customer strategy in the company under study

- Reduce the cost of uptake, upgrade, customer retention

- Reduce financial and human costs

\section{Statement of the Problem}

\section{Phase 1: Environmental Analysis}

After reviewing the business environment, Saba and its customers, as well as the products used by Saba's corporate customers, also the final products that the company's customers make and participate in their production, the following results were obtained.

Saba Company is a service company that provides services to stone processing

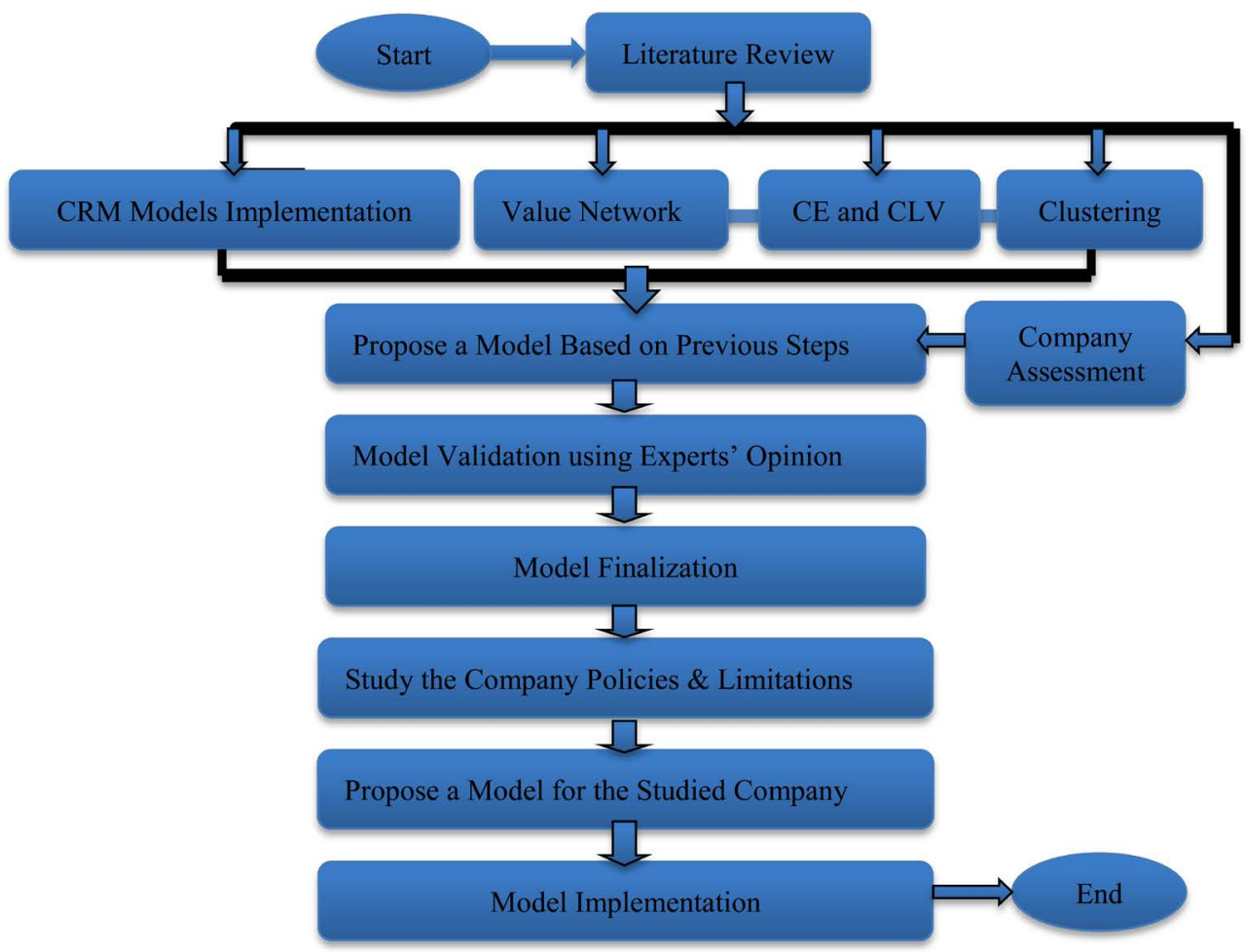

Figure 1. The process of conducting research (CE: Customer Equity; CLV: Customer Lifetime Value). 
companies (it supplies raw materials to these companies). This company is an outsourcing company. It uses the resources of other companies to meet the demands of its customers. It does not produce any kind of product. Organizations that can be part of the organization's clients include: stone processing companies, mining rock companies, as well as organizations of their own type.

\section{Phase 2: Data Collection Based on Purpose}

The data used in this study was obtained by interviewing the managers of Saba Company and their customers. The data needed for the following steps of the study were collected.

\section{Phase 3: Data Integration}

The customer value (CV) data is obtained from Saba's database, as well as interviews with its executives and its customers' managers, which are combined with each other for each customer. In this research, the executives of the center have been fully involved in determining the value of the customers due to their importance. In order to optimize the efficiency of clustering algorithms, just like the classification algorithms, it is necessary to normalize the datasheet so that no specific variables or any sub-set of variables dominate the analysis. To this end, analysts use the Z-score standardization or Min-max normalization [4]:

$$
\text { Z-score standardization }=\frac{X-\operatorname{mean}(X)}{S D(X)}
$$

In this study, the Min-max method was used to normalize the data set, considering that the variables were relative. Of course, because the criterion for customer value is only customer lifetime value (CLV) of customers, clustering of customers can be the same as classifying cluster centers and sorting them down in descending order based on cluster centers.

$$
\min -\max =\frac{X-\min (X)}{\max (X)-\min (X)}
$$

\section{Phase 4: Calculation of customer value:}

In this phase, the value of each individual customer center is calculated. In this research, customer value is calculated through CLV. To calculate CLV, there are several methods and formulas that after interviewing Saba's executives, including examining different methods for calculating CLV, as well as the type of data available to customers, resulted in the following method for calculating CLV for corporate clients. In this model, it is assumed that all cash flow values are at the end of the period.

If we calculate all the tangible assets of the asset (cash, warehouse, etc.), we can calculate the actual or market value of the company under study from the following equation:

$$
\text { Actual value }=\mathrm{CE}_{\mathrm{c}}+\text { Asset }
$$

In the above relationship, the past information of the company's customers as well as managers' views for the estimation of CLV and customer equity (CE) has been used. 


\section{Phase 5: Customer Segmentation:}

After calculating the lifetime value of corporate customers, the focus is on the segmentation of customers [5] [6] [7]. The clustering method has been used to segment customers. First, the data obtained from the previous steps has been normalized using the minimal-maximal method so that very large or small data does not affect the clustering process. As it was advanced, clustering involves different methods, including:

1) SOM-Kmeans

2) $\mathrm{SOM}$

3) K-Means

4) K-Medoid

5) Expectation Max.

6) Fuzzy Clustering

There are also hierarchical methods, some of which have been investigated.

After the investigations, the K-Means method was selected for data clustering. We also used the hierarchical approach to determine the optimal number of clusters as well as the focus of the managers [8] [9]. MATLAB software was used for data clustering. The specified number of clusters is 6 , as shown in Table 1 .

Figure 2, illustrates the distribution of the centers of the clusters.

The distance between cluster centers are also shown in Table 2.

Table 1. Center of clusters.

\begin{tabular}{ccccccl}
\hline $\mathbf{6}$ & $\mathbf{5}$ & $\mathbf{4}$ & $\mathbf{3}$ & $\mathbf{2}$ & $\mathbf{1}$ & Cluster \\
\hline 0.0107 & 0.0543 & 0.1215 & 0.22 & 0.4357 & 0.8923 & Centers \\
\hline
\end{tabular}

Table 2. Distance between cluster centers.

\begin{tabular}{ccccccl}
\hline CLUSTER 6 & CLUSTER 5 & CLUSTER 4 & CLUSTER 3 & CLUSTER 2 & CLUSTER 1 & \\
\hline 0.8816 & 0.823 & 0.7708 & 0.6723 & 0.5466 & 0 & CLUSTER 1 \\
0.4256 & 0.3814 & 0.3142 & 0.2157 & 0 & 0.5466 & CLUSTER 2 \\
0.2093 & 0.1657 & 0.0985 & 0 & 0.2157 & 0.6723 & CLUSTER 3 \\
0.1108 & 0.0672 & 0 & 0.0985 & 0.3142 & 0.7708 & CLUSTER 4 \\
0.0436 & 0 & 0.0672 & 0.1657 & 0.3814 & 0.823 & CLUSTER 5 \\
0 & 0.0436 & 0.1108 & 0.2093 & 0.4256 & 0.8816 & CLUSTER 6 \\
\hline
\end{tabular}

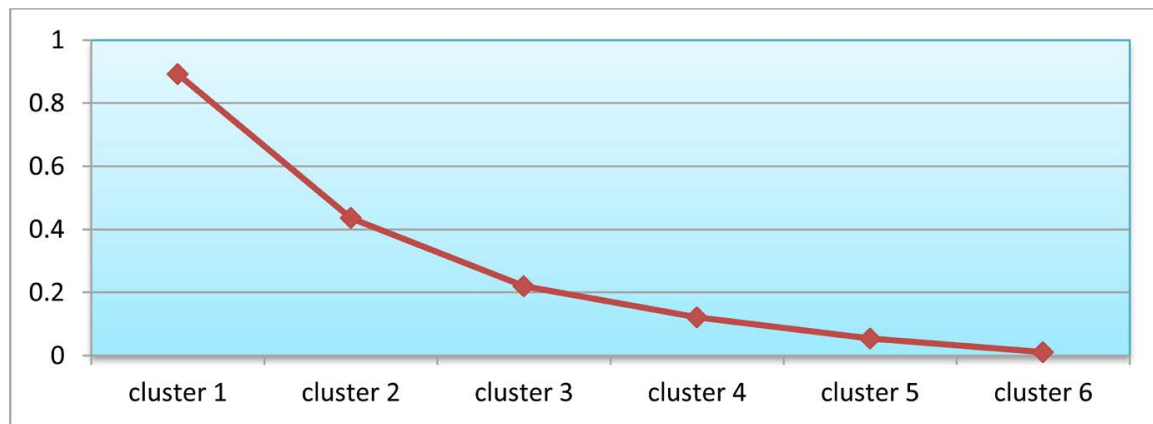

Figure 2. Centers of clusters. 
Phase 6: Drawing a Value Network Between the Organization and Customer Sectors

In this phase of the network, the value is drawn between the organization and the customer segments.

Figure 3 depicts the pre-map of the value network between the company's customer segments.

Phase 7: Primary Analysis of Value Network:

In this section, the model is derived from the value analysis network model provided in [10].

Phase 8: Determining Value Rising Relationships:

This phase consists of two parts. Identifying the important value rings that pass from the center of the two sections of customers and returning to the focus; and second, identifying the increasing value paths that are sent from the focus to a section and returns from the same section to the focus.

\section{Phase 9: Determine the mathematical transfer functions of the value}

After the introduction of loops and increasing paths of value, the value transfer functions for each individual must be determined. In order to obtain the value transfer functions, first, hypothetical and near-reality functions for each path and loop are defined by the researcher. Then the functions were reviewed in a two-hour session, all of which were executed by the site's executives, and the functions that needed to be modified or corrected were identified and the problem was resolved. In general, most of the functions assigned by the researcher for paths and loops were approved by the directors of the center. In the Table 3, the transmission paths and value transferring rings and each value function are shown.

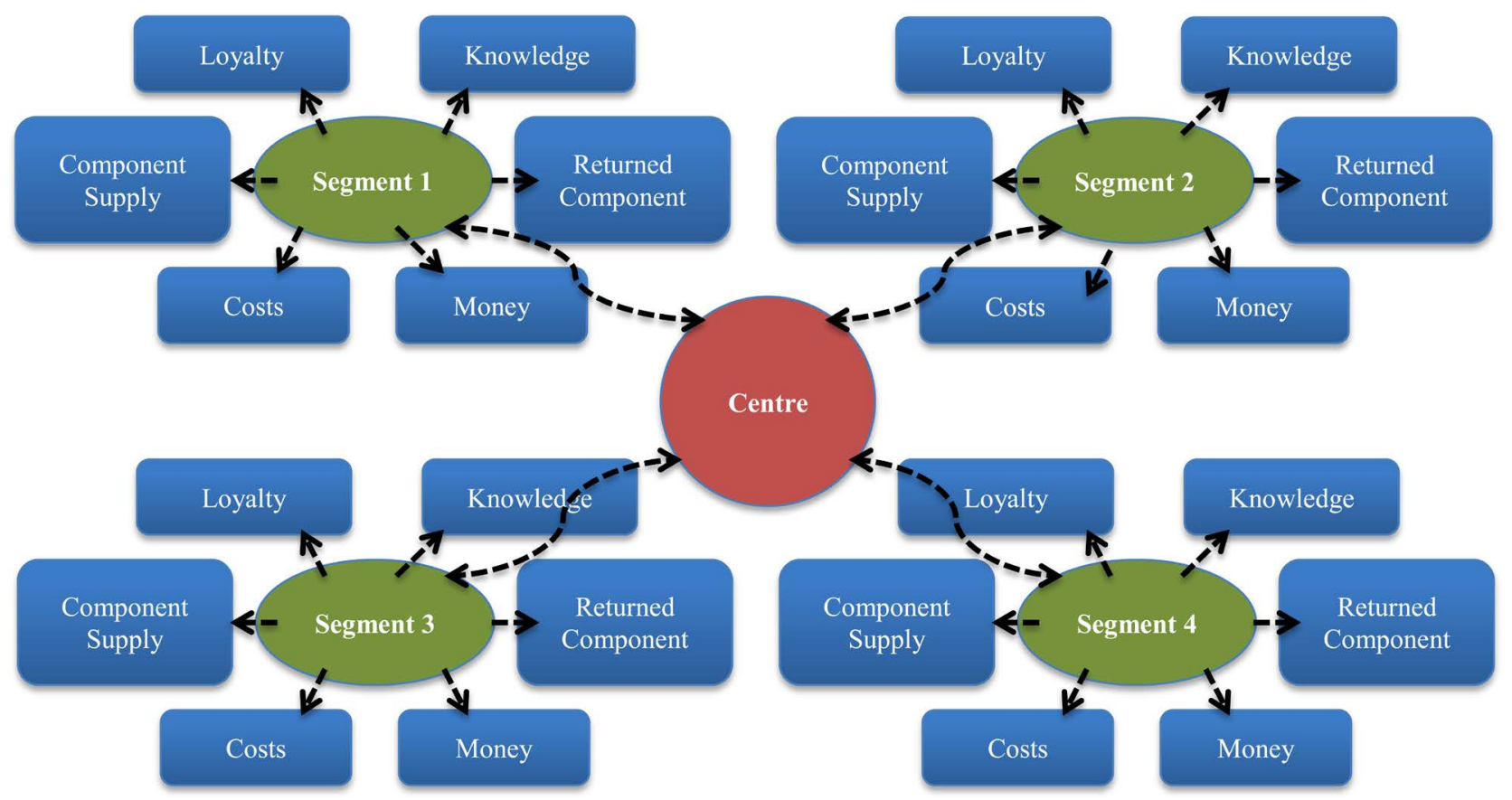

Figure 3. Pre-map of the value network between the company's customer segments. 
Table 3. Selected value paths for a short-term (one year) horizons for mathematical modeling.

\begin{tabular}{|c|c|c|c|c|c|}
\hline Vlue Transmition Function Paremeters & Received Value $r_{s d}$ & Transmitted: Value $t_{s d}$ & Value track Fti.dSiri.dF & Function & Track No \\
\hline$V=2 ; u=80$ & Receive Money & Send components & Ft1.1S1r1.1F & Linear & 1 \\
\hline$v=3 ; u=75$ & Receive Money & Send components & $\mathrm{Ft} 2.10 \mathrm{~S} 2 \mathrm{r} 2,10 \mathrm{~F}$ & Linear & 2 \\
\hline$V=10 ; u=240$ & Receive Money & Send components & Ft3.19S3r3.19F & Linear & 3 \\
\hline$V=7 ; u=130$ & Receive Money & Send components & Ft $4.28 \mathrm{~S} 4 \mathrm{r} 4.28 \mathrm{~F}$ & Linear & 4 \\
\hline$v=5 ; u=75$ & Receive Money & Send components & Ft5.37S5r5.37F & Linear & 5 \\
\hline$o=100 ; v=320 ; w=100 ; u=380$ & Loyalty & Supply commitment & Ft1.3S1r1.3F & Step/Lader & 6 \\
\hline$o=10 ; v=300 ; w=70 ; u=350$ & Loyalty & Supply commitment & $\mathrm{Ft} 2.12 \mathrm{~S} 2 \mathrm{r} 2.12 \mathrm{~F}$ & Step/Lader & 7 \\
\hline$o=500 ; V=1200 ; w=200 ; u=1600$ & Loyalty & Supply commitment & Ft3.21S3r3.21F & Step/Lader & 8 \\
\hline$o=250 ; V=650 ; w=80 ; u=850$ & Loyalty & Supply commitment & Ft4.30S4r4.30F & Step/Lader & 9 \\
\hline$o=100 ; v=320 ; w=70 ; u=360$ & Loyalty & Supply commitment & Ft5.39S5r5.39F & Step/Lader & 10 \\
\hline$o=100 ; v=320 ; w=5 ; u=15$ & Order Plan & Supply commitment & Ft1.4S1r1.4F & Step/Lader & 11 \\
\hline$o=100 ; v=300 ; w=5 ; u=15$ & Order Plan & Supply commitment & $\mathrm{Ft} 2.13 \mathrm{~S} 2 \mathrm{r} 2.13 \mathrm{~F}$ & Step/Lader & 12 \\
\hline$o=500 ; V=1200 ; w=13 ; u=40$ & Order Plan & Supply commitment & $\mathrm{Ft} 3.22 \mathrm{~S} 3 \mathrm{r} 3.22 \mathrm{~F}$ & Step/Lader & 13 \\
\hline$o=250 ; v=650 ; W=10 ; u=30$ & Order Plan & Supply commitment & Ft4.31S4r $4.31 \mathrm{~F}$ & Step/Lader & 14 \\
\hline$o=100 ; v=320 ; w=5 ; u=8$ & Order Plan & Supply commitment & Ft5.40S5r5.40F & Step/Lader & 15 \\
\hline$o=100 ; v=320 ; w=0 ; u=70$ & Order variety & Supply commitment & Ft1.5S1r1.5F & Step/Lader & 16 \\
\hline$o=100 ; V=300 ; w=2 ; u=70$ & Order variety & Supply commitment & Ft2.14S2r2.14F & Step/Lader & 17 \\
\hline$o=500 ; v=1200 ; w=25 ; u=210$ & Order variety & Supply commitment & Ft3.23S3r3.23F & Step/Lader & 18 \\
\hline$o=250 ; v=650 ; w=15 ; u=110$ & Order variety & Supply commitment & Ft4.32S4r3.32F & Step/Lader & 19 \\
\hline$o=100 ; v=320 ; w=7 ; u=60$ & Order variety & Supply commitment & Ft5.41S5r5.41F & Step/Lader & 20 \\
\hline$o=100 ; v=320 ; w=0 ; u=3$ & Order volume & Supply commitment & Ft1.6S1r1.6F & Step/Lader & 21 \\
\hline$o=100 ; v=300 ; w=2 ; u=8$ & Order volume & Supply commitment & Ft2.15S2r2.15F & Step/Lader & 22 \\
\hline$o=500 ; V=1200 ; w=2 ; u=30$ & Order volume & Supply commitment & Ft3.24S3r3.24F & Step/Lader & 23 \\
\hline$o=250 ; v=650 ; w=1 ; u=15$ & Order volume & Supply commitment & Ft $4.33 \mathrm{~S} 4 \mathrm{r} 4.33 \mathrm{~F}$ & Step/Lader & 24 \\
\hline $\mathrm{o}=100 ; \mathrm{v}=320 ; \mathrm{w}=1 ; \mathrm{u}=6$ & Order volume & Supply commitment & Ft5.42S5r5.42F & Step/Lader & 25 \\
\hline $\mathrm{o}=1 ; \mathrm{v}=3 ; \mathrm{w}=1 ; \mathrm{u}=10$ & Order variety & Product knowledge & Ft1.9S1r1.9F & Step/Lader & 26 \\
\hline$o=1 ; V=3 ; w=1 ; u=10$ & Order variety & Product knowledge & $\mathrm{Ft} 2.18 \mathrm{~S} 2 \mathrm{r} 2.18 \mathrm{~F}$ & Step/Lader & 27 \\
\hline$o=2 ; v=7 ; w=3 ; u=50$ & Order variety & Product knowledge & $\mathrm{Ft} 3.27 \mathrm{~S} 3 \mathrm{r} 3.27 \mathrm{~F}$ & Step/Lader & 28 \\
\hline$o=2 ; v=7 ; w=2 ; u=35$ & Order variety & Product knowledge & Ft4.36S4r4.36F & Step/Lader & 29 \\
\hline$o=2 ; V=7 ; w=0 ; u=25$ & Order variety & Product knowledge & Ft5.45S5r5.45F & Step/Lader & 30 \\
\hline$o=5 ; V=10 ; w=2 ; u=5$ & Order variety & Best Price & Ft1.7S1r1.7F & Step/Lader & 31 \\
\hline$o=5 ; v=10 ; w=2 ; u=7$ & Order variety & Best Price & Ft2.16S2r2.16F & Step/Lader & 32 \\
\hline$o=5 ; v=30 ; w=15 ; u=35$ & Order variety & Best Price & Ft3.25S3r3.25F & Step/Lader & 33 \\
\hline$o=5 ; v=15 ; w=5 ; u=25$ & Order variety & Best Price & Ft4.34S4r4.34F & Step/Lader & 34 \\
\hline$o=5 ; V=20 ; w=5 ; u=10$ & Order variety & Best Price & Ft5.43S5r5.43F & Step/Lader & 35 \\
\hline$o=5 ; V=10 ; w=0 ; u=0$ & Order volume & Best Price & Ft1.8S1r1.8F & Step/Lader & 36 \\
\hline$o=5 ; V=10 ; w=0 ; u=5$ & Order volume & Best Price & $\mathrm{Ft} 2.17 \mathrm{~S} 2 \mathrm{r} 2.17 \mathrm{~F}$ & Step/Lader & 37 \\
\hline$o=5 ; V=30 ; w=10 ; u=40$ & Order volume & Best Price & Ft3.26S3r3.26F & Step/Lader & 38 \\
\hline$o=5 ; V=15 ; w=7 ; u=25$ & Order volume & Best Price & Ft4.35S4r4.35F & Step/Lader & 39 \\
\hline$o=5 ; V=20 ; w=5 ; u=20$ & Order volume & Best Price & Ft5.44S5r5.44F & Step/Lader & 40 \\
\hline
\end{tabular}




\section{Phase 10: Solving the mathematical model of the network value:}

Up to nine phases of the network of value were determined among customer segments and loops and long-term value-added paths [6] [7]. To this phase, the value of which routes and rings were long-term considered. But in this phase, the horizons are one year old and limited. So again, the value network is plotted and value paths are identified in the short run. In this section, the problem of mathematical modeling of the value network is investigated in a state where the network consists of important value rings and increasing value paths. In this problem, only the loops and paths that are considered to be the focal point are considered for the error and the time to solve. On the one hand, it is assumed that there is no uncertainty in the choice of transfer functions. In the two sessions that were held with the directors of the center, the directions and value circles were examined.

The sensitivity analysis of the value of the target function to the boot is shown in Figure 4.

Previously, in defining the limitations of the problem, it was assumed that the paths and rings of the value transfer with particular behavior and limitations of value [8], and there was no uncertainty in the choice of functions that were selected by the opinion of the focal experts. Now in this section it is assumed that there is no certainty about the choice of functions by experts. Therefore, in this case, the behavior of any value path with a probability between 0 and 1 is assigned to the transfer function values. So that the sum of these probabilities for each loop and the path on different functions is always equal to 1 . So we have [10]:

$$
\begin{aligned}
& \exists p r_{d, f} ; \forall d=1,2, \cdots, 40 ; \forall f=1, \cdots, F \quad \ni \quad 0 \leq p r_{d, f} \leq 1, \sum_{f=1}^{F} p r_{d, f}=1 \\
& \exists p r_{l, f} ; \forall l=1,2, \cdots, 36 ; \forall f=1, \cdots, F \quad \ni \quad 0 \leq p r_{l, f} \leq 1, \sum_{f=1}^{F} p r_{l, f}=1
\end{aligned}
$$

In the above relations $\mathrm{F}$ refers to the total number of functions. In these situations, the number of possible states defined by the $\mathrm{p} 1$ problem is equal to $76 \mathrm{~F}$, but in practice each loop and path correspond to a small number of values

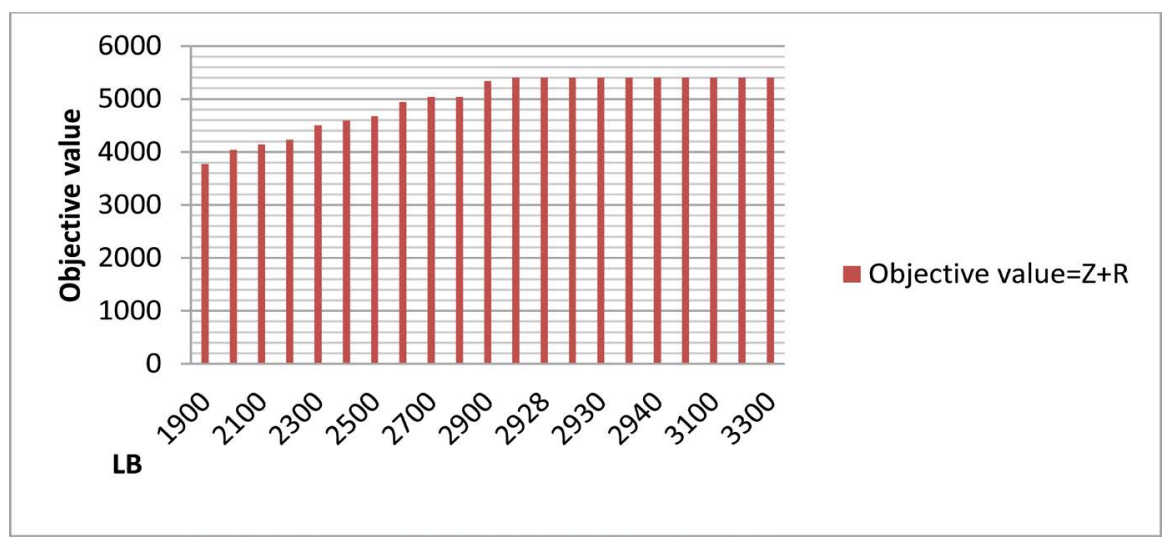

Figure 4. Sensitivity analysis of the value of the target function to the boot. 
transfer functions [9]. If the number of these functions for a ring 1 is equal to $\mathrm{ml}$ and for the path $\mathrm{d}$ to $\mathrm{md}$, then the number of possible states of the problem is equal to $S$ [10]. If we want to define the issues for the six transfer value functions introduced in the literature review section, the number of possible scenarios of the definition of the problem is too great and irreparable. Of course, it might be possible to write an algorithm to examine these states that the discussion around it is beyond the scope of this research. Regarding the probabilities for each path with each transfer function, to match the behavior of each path, there are four possible ways to solve the problem, which we consider to be p11, p12, p13, p14, respectively, with four different probabilities of occurrence as shown in Table 4.

The above mentioned problem is modeled into four modes and entered into LINGO. The problem is solved with hypothesis 250. The values obtained for $t$ and $r$ are also shown in Table 5.

As you can see, the optimal value of sending to the paths in different problem states (issues p11, p12, p13) is the same. Namely, changing the limitations of the objective function has no effect on the allocation of any path. This is mainly due to the equality of some variables $(t(4)=t(5)=t(6)=t(7))$. Also, in the p14 problem, due to the type of functions, as well as the parameters of the parameters, the optimal value Submissions to most routes are zero. That is, in the p14 problem with Boot2, 250 does not create any change in the value of the target function and the values of the optimal value sent to the paths.

So the optimal answer is always in the range below:

$$
\begin{gathered}
r^{*}-\sigma \leq \text { Optimal total received value } \leq r^{*}+\sigma \\
121-83.781 \leq \text { Optimal total received value } \leq 121+83.781 \\
37.219 \leq \text { Optimal total received value } \leq 204.781
\end{gathered}
$$

From the above, we conclude that the change in the objective function limits (value transfer functions) in the sample problem above, which is a small part of

Table 4. The behavior of each path with each value function.

\begin{tabular}{ccc}
\hline State & Problem & $\operatorname{pr}_{\mathrm{s}}=\prod_{d=1}^{7} \operatorname{Pr}_{d f}$ \\
\hline$=1$ & $p_{11}$ & $\operatorname{Pr}_{1,2} \operatorname{Pr}_{2,5} \operatorname{Pr}_{3,1} \operatorname{Pr}_{4,4} \operatorname{Pr}_{5,5} \operatorname{Pr}_{6,4} \operatorname{Pr}_{7,4}=0.08$ \\
$=2$ & $p_{12}$ & $\operatorname{Pr}_{1,2} \operatorname{Pr}_{2,5} \operatorname{Pr}_{3,1} \operatorname{Pr}_{4,4} \operatorname{Pr}_{5,5} \operatorname{Pr}_{6,4} \operatorname{Pr}_{7,5}=0.32$ \\
$=3$ & $p_{13}$ & $\operatorname{Pr}_{1,2} \operatorname{Pr}_{2,5} \operatorname{Pr}_{3,1} \operatorname{Pr}_{4,4} \operatorname{Pr}_{5,5} \operatorname{Pr}_{6,5} \operatorname{Pr}_{7,4}=0.12$ \\
$=4$ & $p_{14}$ & $\operatorname{Pr}_{1,2} \operatorname{Pr}_{2,5} \operatorname{Pr}_{3,1} \operatorname{Pr}_{4,4} \operatorname{Pr}_{5,5} \operatorname{Pr}_{6,5} \operatorname{Pr}_{7,5}=0.48$ \\
\hline
\end{tabular}

Table 5. Lingo software outputs.

\begin{tabular}{lcccccccc}
\hline & 1 & 2 & 3 & 4 & 5 & 6 & 7 & rs \\
\hline state $1: P_{11}$ & 2 & 0 & 0 & 00 & 00 & 00 & 00 & 0.08 \\
state $2: P_{12}$ & 2 & 0 & 0 & 00 & 00 & 00 & 00 & 0.32 \\
state $3: P_{13}$ & 2 & 0 & 0 & 00 & 00 & 00 & 00 & 0.12 \\
state $4: P_{14}$ & 2 & 0 & 0 & 0 & 0 & 0 & 0 & 0.48 \\
\hline
\end{tabular}


the network, changes the optimal response too much. By comparing the optimal response of the received and received paths in the $\mathrm{p} 3$ problem with $\mathrm{p} 11, \mathrm{p} 12$, p13, p14, we conclude that the change in the objective function limitations (values of the functions of the translation) creates a large change in the optimal solution of the problem. Therefore, we must pay attention to the choice of transfer functions. In this research, the choice of functions of transfer of value in the uncertainty mode is limited in a particular case. But it is likely that using an efficient algorithm; it can be investigated in all possible ways. If this is done, more precise results can be obtained. Furthermore, the optimal answer to the optimization problem can be more accurate. Due to the complexity of the topic, which it is out of the scope of the current paper, we're not well satisfied with the results.

\section{Conclusion}

The customer is the most important asset of the center. The customer can benefit from the top (first and second) customers with the most profits with the lowest cost. So the organization should keep these customers in any way. The level of customers' ghosts in the second part is about half the customers in the first part. Users in the first and second segments are not sensitive to price changes. But they are sensitive to supply commitment and quality. Most can benefit from third-party customers (The number of third-party customers is high). Third-party customers have a high potential value that organizations can take with them with an appropriate program. So you have to invest in these customers (The focus must be to strengthen the value-added path of third-party customers). The profits earned from customers in the fourth part, despite the fact that the number of customers is equal to half the third. This is partly due to the low level of customer gaming in the segment and the amount of purchases and loyalty. However, customers in this segment or cluster have a fairly high potential value that an organization can achieve with an appropriate program. Therefore, customers should be invested in these third-fourths. Third, and fourth, users are sensitive to the price, quality, and commitment. Users in the third and fourth sections have the ability to upgrade to the higher sectors. Pupils who are on the fifth floor have a potential value. Dependency and the loyalty of these customers to the organization are low. However, the organization can acquire some of the potential value of these customers with an appropriate program. Users in this sector are very sensitive to the quality and price. So, the profitability of these customers is low. In order to gain the loyalty and potential value of customers, these sectors should provide high quality services with the least margin of profit to make it difficult for the supplier to change. That needs a lot of work. Therefore, the cost of maintaining these customers is high. Investing in customers in section 6 is not recommended. The identified routes are the most important value paths between the core and the customer segments. All paths are required to be active. Because the inactivity of even a value path can make a lot of damage to the company in the medium to long term, or even in some time to the short 
term. Value rings are activated when all the value paths are active. The commitment to supply one Oral-to-mouth advertising is important in the third, fourth and fifth segments. There are also mouth-to-mouth advertisements inside each section. The discussion around it is beyond the scope of this research. But if oral-to-mouth advertising is activated in sections, it will also be activated in the sectors. The channels of communication with customers in this organization are: telephone, mobile, letter, fax, email, communication. There is no kind of interconnection between channels. There is no database type for storing customer data (only customer account data is stored). The goal of all companies is to produce the ultimate quality products at the right time, and at the lowest cost. In the whole center, in order to increase its loyalty and obtain the potential value of its customers, it must activate the relevant value paths, design and implement appropriate communication programs, and balance the price and quality of services. This balance is adjusted by changing the customer's sensitivity to invoices. So far, Saba has traditionally been doing business and there is no comprehensive way to manage its customers, but using this model can first classify its customers based on the profitability that it has for them, and based on each customer treats the value that creates. Furthermore, it heightens important value paths, and boosts them more and more at a lower cost. In general, the company can design a suitable marketing program and focus its activities on a highly competitive market.

\section{Acknowledgements}

The research has been supported by Tarbiat Modarres University, Shahid Beheshti University, and Khatam Al-Anbiya University of Tehran.

\section{References}

[1] Agrawal, M. (2005) Data Warehousing Mining to Knowledge Management. 2007.

[2] Allee, V. (2000) Reconfiguring the Value Network. Journal of Business Strategy, 21, 1-6. https://doi.org/10.1108/eb040103

[3] Baxter, R. and Matear, S. (2004) Measuring Intangible Value in Business-to-Business Buyer-Seller Relationships: An Intellectual Capital Perspective. Industrial Marketing Management, 33, 491-500.

[4] Bayo'n, T.S., Gutsche, J., et al. (2002) Customer Equity Marketing: Touching the Intangible. European Management Journal, 20, 213-222. https://doi.org/10.1016/S0263-2373(02)00037-3

[5] Berger, P.D. and Nasr, N.I. (1998) Customer Lifetime Value: Marketing Models and Applications. Journal of Interactive Marketing, 12, 14.

[6] Berger, P.D. and Bechwati, N.N. (2001) The Allocation of Promotion Budget to Maximize Customer Equity. Omega: The International Journal of Management Science, 29, 49-62. https://doi.org/10.1016/S0305-0483(00)00023-2

[7] Bitran, G.R. and Mondschein, S. (1996) Mailing Decisions in the Catalog Sales Industry. Management Science, 42, 1364-1381.

https://doi.org/10.1287/mnsc.42.9.1364 
[8] Blattberg, R.C. and Deighton, J. (1996) Manage Marketing by the Customer Equity Test. Harvard Business Review, 74, 136-144.

[9] Blattberg, R.C. and Thomas, J.S. (1997) Dynamic Pricing Strategies to Maximize Customer Equity. Evanson, Northwestern University.

[10] Hosseini Khamene, M. (2010) Optimization of Customer Value Using Industry Value Network Analysis Approach. Ph.D. Thesis, Tarbiat Modares University, Tehran. 